\title{
In memory of doctor Miklós Ujvárosi, founding teacher of the scientific school of Hungarian weed biology and weed control specialists on the 40th anniversary of his death
}

\author{
Janos Molnar* \\ Independent EU expert, Budapest, Hungary
}

\begin{abstract}
In memory of Dr. Miklós Ujvárosi (1913-1981), founding teacher of the scientific school of Hungarian weed biology and weed control specialists on the occasion of the 40th anniversary of his death: This is the unique scientific school preparing herbologists to have necessary weed biology and weed control knowledge. His students continue and develop the scientific activity of the professor. The need for meetings has grown into a series of regular meetings for herbologists wherever they work.
\end{abstract}

Dr. Miklós Ujvárosi (1913-1981), the scientific school-creating teacher of specialists with necessary weed biology and weed control knowledge, has unfortunately not been among us for last forty years. As his students, we remained true to his professional spirit and carried it on. Fortunately, between 1964 and 1977, a total of 11 of his students were able to work directly for him in the village Vácrátót, in the research institute and the botanical garden. For us, Uncle Miklós himself led 4 national weed control courses in Hungary (1967-1968, 1968-1969, 1975-1976 and 1980-1981) with a total of 52 professionals. Relying on the high level of professional knowledge thus acquired, these colleagues, as a result of their thorough and persistent work became recognized and respected weed biology and weed control specialists of the plant protection stations of counties in Hungary.

At that time, I myself worked as the coordinator of county plant pathologists at the Plant and Soil Protection Center in Budapest, with the plant protection product licensing and product development representatives of plant protection companies, similarly coordinating their work. I asked my bosses to allow me to take the weed course as well, because the professional knowledge is needed for the county's weed specialist colleagues to accept me professionally as their coordinator. This is how I was able to complete the next course, the IV weed knowledge course in 1980-1981. At our closing banquet, in the village Tass - one of the days after Uncle Miklós' funeral - we had the idea that our team from different parts of the country, but also well forged humanely, should be kept together in some way in the future. As a course leader, I was asked by my teammates at the time to go around the topic and to find Dr. Aurél Kádár, the weed leader of the ministry, with our idea. As a result of thorough preparatory work, we established the Dr. Miklós Ujvárosi Weed Knowledge Society in the village Tengelic in 1984, were Dr. Aurél Kádár elected as its president and I was elected as its secretary. I fulfilled my honorable mandate in the first 5 years, when the

*Corresponding author:janos.m33@gmail.com 
practice of regular annual meetings developed, which has been working well over the years, and which has been developed over the years, adapted to the circumstances. Due to my work abroad, my secretary assignment, which is associated with day-to-day organizational activities, was transferred to Ádám Tóth, but I have been attending the regular annual meetings together with the others ever since.

The straightforward continuation of the Dr. Miklós Ujvárosi Society for the Weed-Free Environment Foundation, founded in 2004, resp. its legal successor is the Dr. Miklós Ujvárosi Foundation for a Weed-Free Environment, which held its 38th annual meeting in 2021, which took place online, in accordance with the present circumstances, in accordance with the regulations. In previous years, during the usual 2.5-day annual professional meeting, together with the Hungarian Weed Research Society, which joined us in the meantime, we listened to scientific and scientific-popular professional lectures on weed biology and weed control. Every year we award professional prizes: the Dr. Miklós Ujvárosi Memorial Medal is awarded to a senior colleague for his outstanding professional work, and the Dr. Károly Hunyadi Memorial Medal is awarded to a young colleague based on his professional work with encouraging results, and Golden Cotyledon Medal is awarded to 2-3 colleagues also for their outstanding professional performance. During the meeting, the working group on herbicide resistance and the editorial board of our journal on weed research and technology meets separately. We compete with photos of herbologist colleagues on weed biology and weed control combined with an exhibition of the best photos. We also compete for their home-made grape wines and fruit brandies made by our weed biology and weed control colleagues, as well as their sausages and salamis combined with a cozy tasting. During the break, we also go to the hotel gym and go for a swim in the hotel pool. Our cozy closing dinner ends with the singing of Hungarian folk songs and a frantic dance of Hungarian "Csárdás".

As a continuation of Uncle Miklós' most important professional legacy, since 1985 the teachers of the V-XII weed knowledge courses have been appointed from among the former staff and students graduated before the same courses. Until the XII course, these courses were attended almost exclusively by plant protection specialists working in the counties' Plant Protection Stations or in the Plant and Soil Protection Directorate or Department of the Government Offices. Life has brought about the fact that the majority of the graduates of the courses, as a result of their outstanding work, moved up the official ladder within the plant protection network, or sooner or later found their calculation in the private sector. That is why more and more courses were needed to held. The rhythm of life, such as retirements and the increase in the natural desire for knowledge, also strengthened these processes. The courses were conducted according to the method developed by Uncle Miklós. The professionals participated in a total of 10 weeks of field practice over two years. In the winter, they received 5 weeks of theoretical training on weed biology. During this time, they made their herbarium containing about 600-800 plant species. In each case, the course ended with a practical exam in a field. The XII course (2018-2019) was unusual because it was organized by the Foundation and funded by the private sector. Of course, this course also had a history. The membership of the Company is open, i.e. all professionals involved in the research and education of weed biology and weed control are free to join us and participate in our meetings and events. Over the years, many young people who wanted to study had joined who had previously wanted to take a course, but did not have the opportunity to do so. They have worked in the profession for years, in the fields of research and development, trade, or agricultural production. With support of their forward-thinking employers, and some, in part or even in full, they wanted and were able to fund such further training in order to further increase their professional knowledge. A total of about one hundred students passed eight courses on their weed knowledge acquired during the course. 
The national field weed surveys started by Uncle Miklós were carried out consistently from time to time on all significant soil types at the settlement boundary designated by him. As a result of the five field and one plantation surveys so far, we have a good view of the domestic weed flora, its changes, trends, especially the order of weeds of wheat and maize fields. Data from the sixth national weed survey of wheat and maize fields are currently being processed. We hope that the current weeding picture of the country will soon emerge and that, as in the past, we will be able to enrich ourselves with high-quality professional lectures and well-illustrated professional publications at plant protection science days and other scientific events.

The openness of the company, inspired by Uncle Miklós' school-creating work, is also well characterized by the involvement of weed control specialists from the surrounding countries in the company's activities, as well as providing them with professional materials and additional professional information and supporting professional contacts. My more than half a century of insight into and active participation in domestic and foreign plant protection, as well as my presentation in Russian at an online conference organized by the Krasnodar Agricultural University in the autumn of 2020, I also experienced the importance of school creation internationally. Based on my foreign outlook, I was able to make sure we were on the right track.

At the personal request of the board of trustees of the Dr. Miklós Ujvárosi Foundation for Weed-Free Environment, I collected the available 50-item documents of Dr. Miklós Ujvárosi's school-creating work and handed them over to the Plant Protection Museum in the village Velence (Hungary). In this way - as a first step - the request Dr. Miklós Ujvárosi occupy his rightful place in the museum based on his exemplary work was fulfilled. Of course, there is still room for further research, so in the near future a colleague with a research vein will hopefully find even more items for us in Uncle Miklós's incompletely researched legacy.

In addition to the presentation of the collected professional materials, the article mentioned as a result of my collection - mentioned in the previous paragraph - contains information about the most important commemorations related to the anniversary of Uncle Miklós' birth / death and the more important professional activities of his students. During the collection of the documents of Dr. Miklós Ujvárosi's school-creating work and their placement in the Plant Protection Museum, I found the following: Dr. Miklós Ujvárosi received documents at the Plant Protection Museum in the village Velence, where Dr. Emil Pocsai registered 50 items. A presentation table of Dr. Miklós Ujvárosi's school-creating work was set up in the village Velence, with 9 items by Dr. Emil Pocsai at the Plant Protection Museum. A memorial room of Dr. Gábor Fekete was established in the village Vácrátót in 2019, where the legacy of Dr. Bálint Zólyomi, Dr. Miklós Ujvárosi and Dr. Rezső Soó can be further researched by reviewing the professional materials placed in the 3 rooms on site, of course only with proper research permission. We are glad that the need for a meeting in August 1981, created by the members of the IV weed course, has grown into such a series of regular professional meetings. I am satisfied with the fact that there are regular professional meetings, such as the above-mentioned weed meeting (together with the Hungarian Weed Research Society), as well as the Plant Protection Science Days, Agricultural Chemistry Society, CEUREG Forum, the monthly Plant Protection Club, university, technical, pensioner our meetings, etc. is. We understand this in particular as we move towards online meetings as a result of our willingness to compromise, but we are very confident that our previous wide-ranging professional meetings will return as soon as possible.

Finally, it is necessary to mention our inevitable, but eagerly executed activity, that we honorably commemorate the weed biology and weed control colleagues who died in the 
meantime, especially their exemplary professional activities at the beginning of our regular annual meeting.

It can be exemplary for other professional companies that our weed society, led by the board of the Dr. Miklós Ujvárosi Foundation for a Weedless Environment, has not forgotten about the satisfaction of all of us, the involvement of young people and the change of generations. The transfer of seniors 'decade experience to juniors is working successfully. The initial professional outcomes of young people can be reassuring to older colleagues. Healthy continuous generational change is taking place before our eyes. We very much hope that in the future this positive trend will continue in the same way as before. In order to maintain and implement this correct and consistent trend in the future, I wish a lot of strength and good health to all of our dear colleagues working in the scientific weed school established as a result of the exemplary activity of Dr. Miklós Ujvárosi!

\section{References}

1. M. Ujvárosi, Our Most Important Field Weeds (Agricultural Publishing House, 1951)

2. M. Ujvárosi, Weeds, Weed Control (Agricultural Publishing House, 1957)

3. M. Ujvárosi, Weeds (Academic Publishing House, 1973)

4. M. Ujvárosi, Weed Control (Academic Press, 1973)

5. J. Molnar, Hungarian Journal of Plant Protection, 81, 338 (2020)

6. J. Molnar: Hungarian Journal of Weed Research and Technology, 21 (1), 79 (2020)

7. R. Novák at all, Arable Weeds of Hungary, Fifth National Weed Survey, pages 1-95 (2007-2008) 